\title{
SMALL BUSINESS WORKERS AND OWNERS SHOULD HAVE AN EASIER WAY TO SAVE FOR RETIREMENT
}

\section{Now is the time for Texas leaders to act}

The COVID-19 pandemic has negatively affected more than half of small business owners in Texas. Small business workers' access to retirement savings dropped during the pandemic, and concerns about having enough money to cover health care or living expenses in retirement are growing.

\section{More Texans Need Ability to Save}
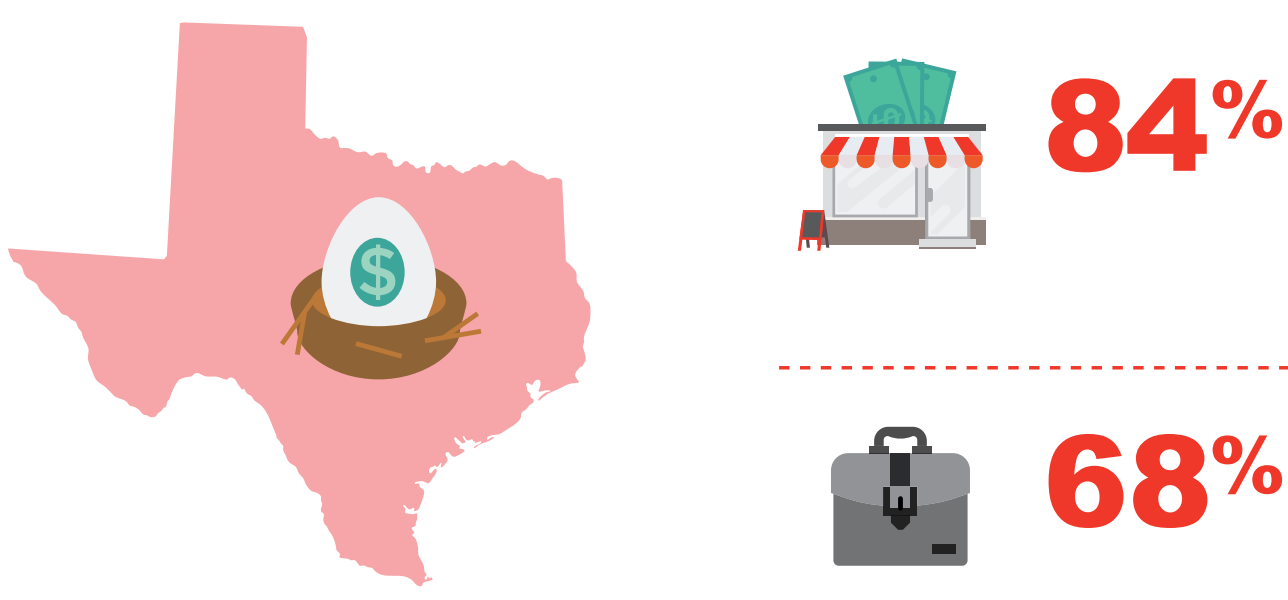

agree that being able to offer a voluntary, portable retirement savings program would help local small businesses attract and retain quality employees and stay competitive.

\section{Concerns Raised About the Impact of Inadequate Savings}

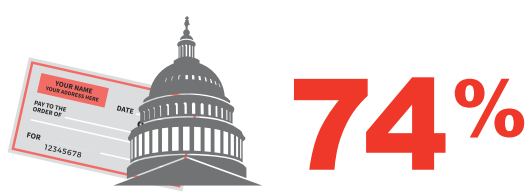

are concerned that Texans haven't saved enough and could end up reliant on public assistance.

\section{$47 \%$

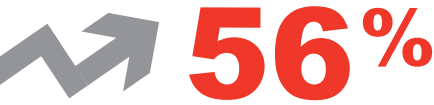

express increased concern about themselves and their employees having enough money to cover health care or living expenses in retirement.

\section{Offering A Workplace Savings Plan is Challenging}

\section{$66 \%$}

Increased number of employers do not participate in or offer a retirement savings plan.
Why don't Texas small businesses offer retirement savings?

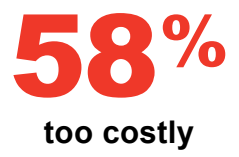

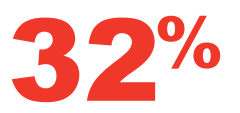

too time consuming 